\title{
CONSTRUCTIONS WITH PRESS_MOUTH COLLOCATION
}

\author{
Temenuzhka Seizova-Nankova*, Mehmed Muharem**
}

\begin{abstract}
The article examines the whole population of press_mouth collocation in order to explore the hypothesis of the construction as a basic linguistic unit used spontaneously by native speakers in discourse. The findings are relevant to foreign language learners especially whose own language (in this case Bulgarian) differs so dramatically from English.
\end{abstract}

Key words: collocations, directionality of relations, corpus-driven approach, 'valency' constructions, construction grammar

\section{Introduction}

One basic hypothesis that has been raised (Goldberg 1995; Croft 2001; SeizovaNankova 2016) concerns the notion of 'construction' as a basic linguistic unit on every level of analysis. The main objective of the paper is to give the knowhow of carrying out an investigation of authentic linguistic data in the endeavor of finding the different constructions of the press_mouth collocation. Thus, the paper is intended to show how knowledge of recent developments in linguistics can be applied to practical purposes in students' projects. In that sense it hopefully serves as a kind of bridge between theory and practice as it gives, by way of illustration, some instruction of how to approach language-in-use. Such descriptions are a great challenge to the researcher as they cannot be carried out without the help of proper methodology.

Part 1 is an introduction to the structure and general aims of the paper. Part 2 consists of a concise description of previous research in the field. Part 3 deals with the methodology used. Part 4 includes the analysis proper by giving a stepby-step instruction in bringing to light the main properties of the constructions as well as exhibiting the comparatively high degree of complexity of the internal structure of the collocation. Parts 5, 6 and 7 summarize the variety of valency constructions used by native speakers (NSs) based on the BNC, more specifically

\footnotetext{
* Assoc. Prof. PhD at University of Shumen, Department of English Studies, Shumen, Bulgaria, e-mail: seizova@shu.bg.

** MA student, Linguistics and Translation, Department of English Studies, University of Shumen, Shumen, Bulgaria, e-mail: mehmed.muharem@yahoo.com
} 
the word sketch of the 'noun' mouth (Kilgarriff et al. 2004) including the conclusions and the implications of the results for foreign language linguistics.

\section{Previous research in the field}

Collocations have increasingly received due attention. However, detailed research on VERB+NOUN collocations (NOUN=bodypart terms), focusing on their complex internal structure, so far as we are informed, are few and far between. Lexicogrammar of $V_{-} H A N D(S)$ collocations. A Corpus-driven Approach (Seizova-Nankova 2016) is the monograph that fills this gap and which can be used as a manual to students in terms of descriptive tools, insights about the emergent nature of language, together with highlights in foreign language linguistics. Press_mouth collocation forms a part of the investigation of language-in-use of the keyword mouth which is itself part of the bigger research of collocations with bodypart terms (see App. 1 and 2).

Other related research even though not in the form of a stand-alone monograph is Kudrnáčová's (2004). It deals with rub o's hands and wring o's hands. The corpus samples from the BNC are the same as in Seizova-Nankova (2016) but the approach is different and the results, even though complementary to the ones from the above mentioned monograph, are also different (cf. Seizova-Nankova 2016). It is, however, necessary to note that the results of the corpus-driven approach confirm the idea of the construction as a basic linguistic unit which is a contribution both to typological research and language change.

The understanding of the term 'collocation' has to do with several features most important of which are computational statistics in building the corpus, in our case the word sketch of mouth (Kilgarriff et al. 2004) and directionality. Most verb-centered theories of syntax take the verb to be the pivot of the syntactic structure. However, the corpus illustrates the grammatical and distributional properties of the word mouth, prominent among which is the VERB+OBJECT relation and this fact takes account of the directionality between the keyword, the node mouth in the press_mouth collocation, and the verb itself. Directionality is the other important feature which carries significant consequences with it. It is important to understand that by changing directionality we get different results. To illustrate this, we will take the example with lend a hand collocation and its double object construction lend me a hand (Bybee 2010: 36). Considering the fact that we take mouth as the node and explore the span to the left and right of it, examples such as lend me $a$ hand (the so called double object construction) are excluded from the word sketch corpus by default. On the other hand, the corpus supplies us with other variations of the classical double object construction in which the object complement is formally realized by what is called going beyond the noun phrase realization. Such phrases actually turn out to be even more frequent (Seizova-Nankova 2016). 


\subsection{Research Questions}

The research questions grow out of the empirical data, i.e. the corpus of the whole population which is a typical feature for the approach used. Here are the basic ones:

- what is the number of participants/complements in every instance of use,

- what complement types are they realized by,

- how do they co-occur to form recurrent patterns of use,

- what are the preferred and dispreferred choices of valency constructions.

The basic objective is to test the hypothesis that the (valency) construction is the basic meaningful unit in language use (Seizova-Nankova 2016).

\section{Methods}

The basic method used is the lexical approach to valency theory (Herbst, Schüller 2008; Herbst 2015) in combination with the construction grammar approach to argument structure (Goldberg 1995; Croft 2001). Argument structure constructions and valency constructions are illustrated by the corpusdriven approach (Herbst et al. 2004) in which the notion of frequency is used to exemplify recurrent instances of authentic material drawn from the BNC.

The lexicographic approach applied to the verbal part of the collocation press (OALD online) serves as a starting point to the analysis but is also a way of illustrating how the new technologies have influenced dictionary makers towards reflecting word partnerships.

The detailed procedure applied in 4 . Analysis of press_mouth corpus includes several steps each of which forms essential part of the methodology used. It begins with the dictionary definition - certain selected extracts from the dictionary entry. It is followed by 20 lines of the corpus itself. On this empirical basis every use is classified according to quantitative valency. The participants, the so-called complements of the valency carrier press, show certain range of variation in their formal realization. Most common are [NP]-complements often realized by personal pronouns but there are complements beyond the NP such as [against_NP] and [against/to_NP]-complements in predicate complement unit two (further - PCU2) position and [on/toward_NP]-complements in PCU3 position (these are based on the corpus analysis of press_mouth collocation). That is clearly shown in the complement inventory which comes next and is then illustrated by examples from the corpus. The examples section seems to be a repetition and hence an unnecessary part of the analysis, but it is not. In fact, it presents a stage in the analysis in which the researcher makes a qualitative selection from the corpus and gives the minimum number of illustrative examples 
on which the analysis is carried out. For the reader the criteria of the selection is as yet undisclosed and remains to be illuminated with every step of further distancing away from raw data. The valency patterns formally different are the next step which leads us straight to the valency constructions themselves. The latter carry some idiosyncratic and some general features. Since this process expresses the gradual abstracting away from the empirical material on the way to some degree of generalization, a process which is in itself hard to follow, the descriptive tools described in Seizova-Nankova (2016) meet the challenge.

The basic idea behind constructions is to do with the fact that constructional meaning is achieved partly by the process illustrated in the analysis and partly by the realization that it is a kind of meaning over and above the meanings of the component parts. Explanation for that is to be found exactly in the greater strength between the parts of the collocation and also in its directionality.

\section{Analysis of press_mouth corpus}

For the first time the whole population of press_mouth collocation which consists of 23 hits drawn from the British National Corpus, all in the singular, is explored.

We start with the dictionary definition of press.

The dictionary definition (OALD online)

Press $=$ push $/$ squeeze

[transitive, intransitive] to push something closely and firmly against something; to be pushed in this way

Press $=$ try to persuade

[transitive] to make strong efforts to persuade or force somebody to do something

SYNONYMS PUSH, URGE

Press somebody If pressed, he will admit that he knew about the affair. press somebody for something The bank is pressing us for repayment of the loan

Press somebody to do something They are pressing us to make a quick decision.

Press somebody into something/into doing something Don't let yourself be pressed into doing something you don't like.

Idioms

press (the) flesh (informal) (of a famous person or politician) to say hello to people by shaking hands 
press something home to get as much advantage as possible from a situation by attacking or arguing in a determined way

From what we read in the dictionary it's not clear what is the possible use of the verb press in the close environment of mouth. Its basic meaning comes close to the meaning of pushing and squeezing. However, we get no idea of the reflexive construction which is most common. There is no clue in the definition of its possible use in the non-reflexive construction either. The knowledge we get from the dictionary entry is limited and incomplete. A complete picture of the internal complexity of collocation structure is possible to obtain only as a final result of the study at hand.

\section{Corpus sample}

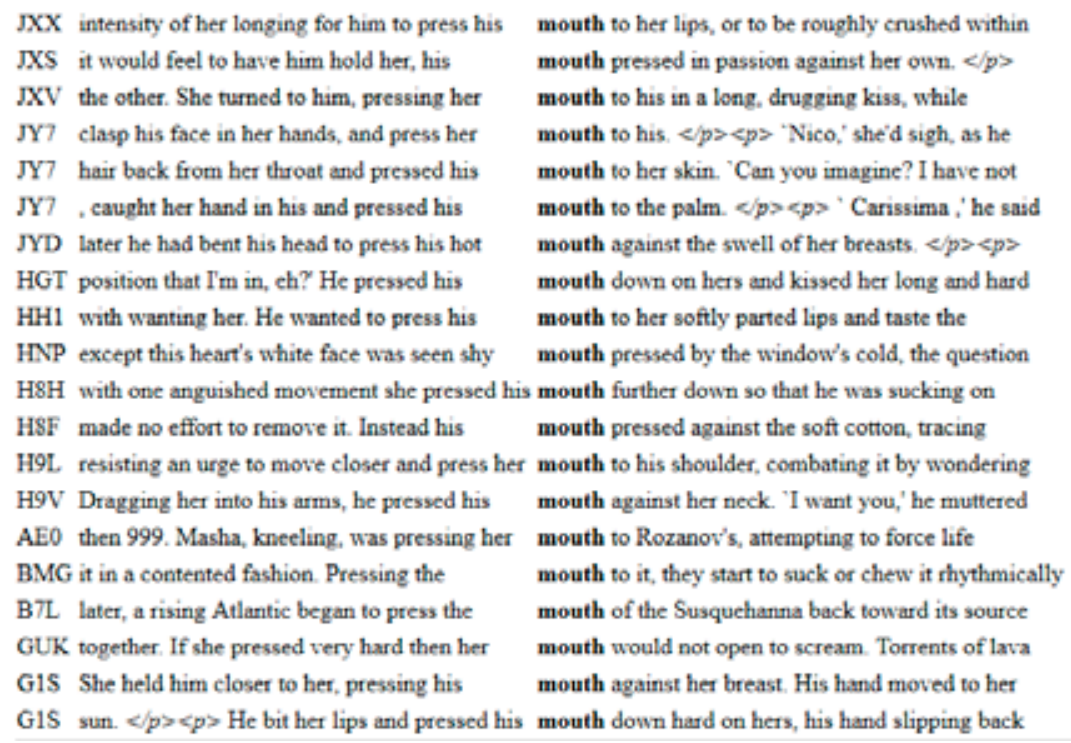

Consider the twenty lines of the corpus data above.

The keyword is used only in the singular. From what we know, lexical countable nouns may occur in both uses - sg. and pl. In this case the lemma mouth occurs only in the singular $-100 \%$.

The noun phrase with the keyword is used in 17 instances with the genitive (his mouth $/ 12$, her mouth $/ 5$ ) of the personal pronouns. The genitive plays a central role in the description of the collocations with mouth. In the whole corpus (23 hits) this relation is 14/his (two uses of which are with pre-modification: his hot mouth and his open mouth - see below) to 6/her. The fact itself speaks of the importance this collocation plays in the interpersonal relationship between the sexes and also of a kind of prevalence in the male behavior which is of importance to gender studies. 
There is only one instance with a zero determiner $(\varnothing / 1$ - consider the example: HNP except this heart's white face was seen shy mouth pressed by the window's cold, the question ...) and 2 instances with the definite determiner (the/2), consider the examples: BMG it in a contented fashion. Pressing the mouth to it, they start to suck or chew it rhythmically, and B7Llater, a rising Atlantic began to press the mouth of the Susquehanna back toward its source ....

Pre-modification. The use of pre-modification combines with zero determiner: $ø$ shy mouth or with the genitive: his hot mouth. Another such example in the whole corpus is his open mouth - consider: FU8hide her revulsion as he pressed his open mouth against hers and began fumbling with the ...

Word order. According to the relative position in the constructions of the verb and the keyword, we found two different word orders. In the first case 'press' precedes the keyword and this is the prevailing model in terms of frequency.

In the second word order, the keyword precedes the verb, but there are only 4 instances in the whole corpus.

\section{QUANTITATIVE VALENCY}

Trivalent uses

4. HH1 with wanting her. He wanted to press his mouth to her softly parted lips and taste the ...

5.H9V Dragging her into his arms, he pressed his mouth against her neck. 'I want you,' he muttered ...

3. $\mathrm{H} 8 \mathrm{H}$ with one anguished movement she pressed his mouth further down so that he was sucking on ...

Quadrovalent uses

1. G1S sun. $</ \mathrm{p}><\mathrm{p}>$ He bit her lips and pressed his mouth down hard on hers, his hand slipping back ...

2. B7Llater, a rising Atlantic began to press the mouth of the Susquehanna back toward its source ...

\section{COMPLEMENT INVENTORY}

$\begin{array}{ll}\text { I optional [NP] } & 1,2,3,4,5 \\ \text { II optional [NP] } & 1,2,3,4,5 \\ \text { III optional [AdvP], [PartP] } & 1,2,3,4,5 \\ \text { IV optional [PartP] } & 1,2\end{array}$


Note: 'With respect to optionality, valency slots will be characterized as to whether a slot must or can be realised by a complement.' (Herbst, Uhrig 2009).

\section{EXAMPLES}

1. G1Ssun. $</ \mathrm{p}><\mathrm{p}>$ He bit her lips and pressed his mouth II downIII hard on hersIV, his hand slipping back ...

2. B7Llater, a rising Atlantic I began to press the mouth of the Susquehanna II back III toward its source IV ...

3. H8Hwith one anguished movement sheI pressed his mouthII further downIII so that he was sucking on ...

4. HH1with wanting her. HeI wanted to press his mouthII to her softly parted lipsIII and taste the ...

5. H9VDragging her into his arms, heI pressed his mouthII against her neck.III 'I want you,' he muttered ...

\section{VALENCY PATTERNS}

$[\mathrm{NP}]$ act-subj + verb/act + [NP] +[against/to_NP] 4, 5

$[\mathrm{NP}]$ act-subj + verb/act $+[\mathrm{NP}]+[\mathrm{AdvP}]$

$[\mathrm{NP}]$ act-subj + verb/act $+[\mathrm{NP}]+[\mathrm{AdvP}]+[$ on/toward_NP $] \quad 1,2$

\section{VALENCY CONSTRUCTIONS}

The valency constructions found are the reflexive and non-reflexive trivalent, the reflexive and non-reflexive quadrovalent and the nominalization construction. The most frequent is the reflexive trivalent construction, followed by the reflexive quadrovalent construction. The non-reflexive quadrovalent construction has just one unique token.

\section{Trivalent uses}

The constructions with trivalent uses are mostly reflexive: 14 instances - only 1 instance of the non-reflexive construction.

\section{THE REFLEXIVE CONSTRUCTION}

As we know the trivalent constructions exhibits subtypes: reflexive and nonreflexive. In this case we are talking about the reflexive construction directed 
to others. The following referential chain [he1->his1->her2] helps visualize the result.

The genitive his in PCU1 position correlates with the subject complement unit (SCU), which means that they share the same referent. This is why we call this type of construction reflexive.

H9V Dragging her into his arms, heI pressed his mouthII against her neck.III 'I want you,' he muttered ...

SCU VHC $_{\text {act:3 }} \quad$ PCU1 PCU2
$\left[\mathrm{NP}_{\text {act-subj_- }}\right.$ 'CAUSER']_pressed ${ }_{\text {act_ }}\left[\mathrm{NP}{ }_{-}\right.$'CAUSED']_[PartP_'GOAL']

\section{THE NON-REFLEXIVE CONSTRUCTION}

In contrast to the reflexive construction here the subject complement unit (SCU) is realized by she, but doesn't share same referent with the PCU1 - his in his mouth. This is why the construction is non-reflexive. There is only one instance.

$\mathrm{H} 8 \mathrm{H}$ with one anguished movement sheI pressed his mouthII further downIII so that he was sucking on ...

$\begin{array}{lccc}\text { SCU NP } & \mathrm{VHC}_{\text {act: } 3} & \text { PCU1 } & \text { PCU2 } \\ {\left[\mathrm{NP}_{\text {act-subj_ }} \text { 'AGENT']_pressed }\right.} & \text { act_- } \\ {[\mathrm{NP}=\text { _AeFFECTED']_[ADV_'DIRECTION'] }}\end{array}$

\section{Quadrovalent uses}

There are 3 instances of the reflexive and only 1 instance of the non-reflexive quadrovalent construction.

\section{THE REFLEXIVE CONSTRUCTION}

G1S sun. $</ \mathrm{p}><\mathrm{p}>$ He bit her lips and pressed his mouthII downIII hard on hersIV, his hand slipping back ...

$\begin{array}{llccc}\text { SCU } & \text { VHC }_{\text {act: } 4} & \text { PCU1 } & \text { PCU2 } & \text { PCU3 } \\ {\left[\mathrm{NP}_{\text {act-subj- }} \text { 'AGENT']_pressed }\right.} & \text { act_[NP_'AeFFECTED']_[ADV_'DIRECTION']_[PartP_'GOAL'] }\end{array}$

This is a case of the reflexive construction. The subject complement unit (SCU) is realized by he, the realization of PCU1 is by the genitive his, which means that SCU and PCU1 share the same referent. It is a realization of the following referential chain: [he1 $->$ his1 $->$ her2]. 


\section{THE NON-REFLEXIVE CONSTRUCTION}

It is possible to encounter examples where this role is performed by the definite article. Consider the next example which represents a unique quadrovalent construction.

B7L later, a rising AtlanticI began to press the mouth of the Susquehanna II back III toward its source IV ...

$\begin{array}{lllll}\mathrm{SCU} & \mathrm{VHC}_{\text {act: } 4} & \mathrm{PCU} 1 & \mathrm{PCU} 2 & \text { PCU3 }\end{array}$

$\left[\mathrm{NP}_{\text {act-subj- }}\right.$ 'AGENT']_press ${ }_{\text {act }}[$ [NP_'AeFFECTED']_[ADV_'DIRECTION']_[PartP_'SOURCE']

In the last example the subject is not a person and the AeFFECTED is a geographic object - the mouth of the Susquehanna, a typical case of lexical metaphor.

\section{NOMINALIZATION}

Four instances of the collocation show another construction type called nominalization. In this case the keyword mouth acts as head of a noun phrase with a reduced relative clause of the past participle of the verb press together with its complement as post-modification. This construction poses great difficulties for the foreign language learner both in its identification and comprehension. It can be easily confused with the ergative construction for the simple fact that the past tense and the past participle of the verb press are homonymous in form especially when the context is not clear enough. The type of nominalization construction can be both active and passive. In this case, it is a realization of the passive construction. Consider the underlined part of the following examples:

H8F made no effort to remove it. Instead his mouth pressed against the soft cotton, tracing ...;

JXS it would feel to have him hold her, his mouth pressed in passion against her own.;

FR3 No. I with a bullet. The corner of her mouth pressed against mine and in concert with ...;

HNP except this heart's white face was seen shy mouth pressed by the window's cold, the question .... .

\section{Results}

This paper is based on a corpus-driven analysis. No previous knowledge of the constructions with press_mouth collocation is available. Thanks to this analysis 
and the results produced we realize that the size of the corpus is irrelevant. The important information is born out by the structures themselves. The preferred choice is the use of genitive forms: 20 instances in the whole corpus. Consider the table below:

\begin{tabular}{|c|c|c|c|}
\hline Genitive & Tokens & \multicolumn{2}{|c|}{ Percentage } \\
\hline His & 14 & $14 / 23$ & $61 \%$ \\
\hline Her & 6 & $6 / 23$ & $26 \%$ \\
\hline
\end{tabular}

Table \#1 Genitive his/her + keyword mouth

Only the genitives his and her are used, with the exception of 3 instances - one with zero determiner and two - with the definite article.

These enter in a great variety of constructions: the reflexive and non-reflexive trivalent, and the quadrovalent both reflexive and non-reflexive and the nominalization construction type. The prevalent construction type with this collocation is the reflexive trivalent with 14 instances, see Table $\# 2$ below.

\subsection{Discussion of Findings}

Considering Table\#2, which summarizes the results, it becomes clear that the most preferred construction is the trivalent one - 15 instances of which 14 instances of use are realized by the reflexive construction, and only one instance illustrates the non-reflexive construction - eg. $\mathrm{H} 8 \mathrm{H}$ with one anguished movement she pressed his mouth further down so that he was sucking on ... . The meaning in both cases is causative thus realizing the caused motion construction (Goldberg 1995) which shows the potential of the collocation.

Next comes the quadrovalent construction -3 instances of use, 2 of which are reflexive, eg. G1S sun. $</ \mathrm{p}><\mathrm{p}>$ He bit her lips and pressed his mouth down hard on hers, his hand slipping back ... and one - non-reflexive, eg. B7L later, a rising Atlantic began to press the mouth of the Susquehanna back toward its source. What is interesting about the last example is the way it is used metaphorically - the mouth of the river is pressed back to its source by the rising Atlantic. The inanimate subject takes on an agentive role and the keyword mouth is used metaphorically; while backward motion is expressed by [ADV]-complement in combination with a complement expressing SOURCE.. 


\begin{tabular}{|l|l|l|l|}
\hline \multicolumn{1}{|c|}{ Construction type } & Tokens & \multicolumn{2}{c|}{ Percentage } \\
\hline Trivalent reflexive & 14 & $14 / 23$ & $61 \%$ \\
Trivalent non-reflexive & 1 & $1 / 23$ & $4.3 \%$ \\
\hline Quadrovalent reflexive & 2 & $2 / 23$ & $8.6 \%$ \\
Quadrovalent non-reflexive & 1 & $1 / 23$ & $4.3 \%$ \\
\hline Nominalization & 4 & $4 / 23$ & $17 \%$ \\
\hline Total & 22 & $22 / 23$ & 95.2 \\
\hline
\end{tabular}

Table \#2 Results from the investigation of press_mouth collocation

The nominalization construction has 4 tokens. No other constructions, the ergative included, have been found in the corpus.

One example is not considered for the fact that it is not a realization of the collocation under discussion, eg. GUKtogether. If she pressed very hard then her mouth would not open to scream. Torrents of lava ... . The verb press and the keyword mouth do not form a collocation in the last example.

\section{Conclusion}

The description of the press_mouth collocation reveals five different construction types such as the trivalent reflexive and non-reflexive, the quadrovalent reflexive and non-reflexive and the nominalization construction. The hypothesis raised about the complex architecture of verb+bodypart collocations is confirmed. The results are harmonious with the constructions of the collocations with hand (Seizova-Nankova 2016). That means that there are enough similarities between them to be compared. Differences point to the specificity of the contexts and the discourses in which the bodypart constructions are used.

\section{Implications}

The analysis of press_mouth collocation gives us some insight about the conceptualization by native speakers of the collocation and, in fact, the way language-in-use in English works. These results will be used to show how the general features that underlie these constructions compare with the general features of the other collocations with mouth, as well as with the bodypart of hand.

Ultimately, these constructions show great typological differences with Bulgarian, the basic one being in the expression of causation. Implications are that such typological features that are so different from one's own tongue present the main challenges in learning and comprehending English. 


\section{References:}

Bybee 2010: Bybee J. Language, Usage and Cognition. Cambridge: Cambridge University Press.

Croft 2001: Croft W. Radical Construction Grammar: Syntactic theory in typological perspective. Oxford: OUP.

Goldberg 1995: Goldberg A. E. Constructions: A Construction Grammar Approach to Argument Structure. Chicago University Press.

Herbst 2014: Herbst T. The Valency Approach to Argument Structure Constructions. - In: Herbst T., Schmid H. J., S. Faulhaber (eds.). Constructions - Collocations - Patterns. Berlin/Boston: de Gruyter Mouton. 167-216.

Herbst 2015: Herbst T. Why Construction Grammar Catches the Worm and Corpus Data Can Drive You Crazy: Accounting for Idiomatic and Non-idiomatic Idiomaticity. Journal of Social Sciences.

Herbst et al. 2004: Herbst T., Heath D., Roe I. F., D. Götz (eds.) A Valency Dictionary of English: A Corpus-Based Analysis of the Complementation Patterns of English Verbs, Nouns, and Adjectives. Berlin: Mouton de Gruyter.

Herbst, Schüller 2008: Herbst T., S. Schüller. Introduction to Syntactic Analysis. A Valency Approach. Tübingen: Narr. 2008,

Herbst, Uhrig 2009: Herbst T., P. Uhrig. Erlangen Valency Pattern Bank - a Corpus-Based Research Tool for Work on Valency and Argument Structure Constructions. Website. $<$ http://www.patternbank.uni-erlangen.de >.[Accessed 26 Sept. 2016]

Jackendoff 2013: Jackendoff R. Genesis of a Theory of Language: From Thematic Roles (Source) to the Parallel Architecture (Goal) (Sort of an Intellectual Memoir). $<$ https://ase. tufts.edu/cogstud/jackendoff/papers/GenesisofPA.pdf> [Accessed 3 March 2016].

Kilgarriff et al. 2004: Kilgarriff A., Rychlý P., Smrz P., D. Tugwell. The Sketch Engine. Proc. Euralex. Lorient, France.

Kudrnáčová 2004. Kudrnáčová, N. On Rubbing and Wringing One’s Hands. - Sborník Prací Filozofické Fakulty Brněnské Univerzity Studia Minora Facultatis Philosophicae Universitatis Brunensis S 10, 2004 - Brno Studies in English 30.

OALD online. Oxford Advanced Learner's Dictionary. $<$ https://elt.oup.com/general content/global/OALD_8_Search?cc $=$ global\&selLanguage $=\mathrm{en}>[$ Accessed September $\left.28^{\text {th }} 2017\right]$.

OCD 2002. Oxford Collocation Dictionary. Oxford: Oxford University Press, 2002.

Seizova-Nankova 2015: Seizova-Nankova, T. How Valency Theory Shakes Hands with Usage. - Litermedia. 30.

Seizova-Nankova 2016: Seizova-Nankova T. Lexicogrammar of V_hand(s) Collocations. A Corpus-Driven Analysis.

Seizova-Nankova 2016a: Seizova-Nankova, T. Valency Constructions at Work: A Case Study. - In: Todorova et al. (eds.) Challenges in English Teaching and Research. Asenevtsi. 21-41. 


\section{Appendices}

App.1 Bodypart terms with frequency per million words in the BNC

\begin{tabular}{|l|cr|cc|}
\hline Bodyparts & Token freq & (per mil) & object_of freq & (per mil) \\
\hline 1. hand & 50278 & 448.2 & 13617 & 2.4 \\
\hline 2. head & 38080 & 339.5 & 12794 & 2.8 \\
\hline 3. eye & 36418 & 324.6 & 11018 & 2.3 \\
\hline 4. face & 29325 & 261.4 & 6693 & 1.8 \\
\hline 5. back & 20203 & 180.1 & 2560 & 1.3 \\
\hline 6. heart & 14766 & 131.6 & 2223 & 1.5 \\
\hline 7. mouth & 9336 & 83.2 & 2098 & 1.8 \\
\hline 8. finger & 8470 & 75.5 & 3522 & 3.2 \\
\hline 9. shoulder & 8203 & 73.1 & 1401 & 1.5 \\
\hline 10. neck & 5608 & 50.0 & 906 & 1.4 \\
\hline 11. ear & 5569 & 49.6 & 1030 & 1.7 \\
\hline
\end{tabular}

\section{App. 2 Word sketch of the lemma mouth}

\begin{tabular}{|l|c|c|}
\hline Object_of & 2098 & $\mathbf{1 . 8}$ \\
\hline 1. shut & 103 & 9.03 \\
\hline 2. open & 488 & 8.97 \\
\hline 3. wipe & 63 & 8.64 \\
\hline 4. twist & 55 & 8.6. \\
\hline 5. curve & 23 & 8.02 \\
\hline 6. tighten & 18 & 7.18 \\
\hline 7. kiss & 19 & 7.05 \\
\hline 8. clamp & 11 & 6.95 \\
\hline 9. part & 13 & 6.86 \\
\hline 10. rinse & 9 & 6.83 \\
\hline 11. compress & 9 & 6.79 \\
\hline 12. stuff & 13 & 6.78 \\
\hline 13. dab & 8 & 6.77 \\
\hline 14. brush & 15 & 6.70 \\
\hline 15. curl & 11 & 6.62 \\
\hline 16. purse & 7 & 6.54 \\
\hline 17. thin & 7 & 6.52 \\
\hline 18. touch & 25 & 6.43 \\
\hline 19. close & 41 & 6.20 \\
\hline 20. press & 23 & 6.06 \\
\hline 21. stretch & 15 & 5.95 \\
\hline 22. keep & 131 & 5.90 \\
\hline 23. fill & 31 & 5.87 \\
\hline 24. tape & 5 & 5.83 \\
\hline 25. burn & 14 & 5.75 \\
\hline & & \\
\hline & & (1) \\
\hline
\end{tabular}

